\title{
THE STRUTURE AND COMPOSITION OF NATURAL VEGETATION TYPES IN LOWER WALAWE BASIN IRRIGATION EXTENTION AREA
}

\author{
${ }^{1.2}$ MAAB Dilhan, ${ }^{1} \mathrm{CNB}$ Bambaradeniya, ${ }^{2} \mathrm{CVS}$ Gunatilleka, \\ ${ }^{3} \mathrm{D}$ Yakandawala, ${ }^{3} \mathrm{FP}$ Amarasinghe \\ IIUCN - The World Conservation Union, Horton Place, Colombo 07 \\ ${ }^{2}$ Department of Botany, University of Peradeniya, Peradeniya \\ International Water Management Institute, Pellawatta, Battaramulla
}

Sri Lanka has experienced a tremendous boost in large-scale irrigation development. The Udawalawe irrigation extension project of the Mahawelli Authority will result in the construction of a left bank main canal from the Walawe River and the establishment of an irrigation system spanning an area of approximately 15,000 ha. A systematic study on biodiversity was carried out in the Lower Walawe Irrigation extension area, from February to August 2001. This paper summarizes the structure and composition of natural vegetation types in the study area, during the pre-development stage. A total of 45 transects (each $50 \mathrm{~m} \times 5 \mathrm{~m}$ ) were demarcated within 16 sites along the dry to arid zone climatic gradient in the study area. Each transect was divided into $10 \mathrm{~m} \times 5 \mathrm{~m}$ sub plots to facilitate sampling and individual plants over $10 \mathrm{~cm}$ in girth were recorded. The data was analysed using ecological indices (Shannon-Wiener index and Simpson's Index) and multivariate analyses using the PCORD4 software

The area consists of 3 major natural vegetation types; dry thorny scrubland (DTF), rock outcrop forests (ROF). and degrade dry zone forest (DDF). A total of 151 plant species, belonging to 52 families were recorded from the above vegetation types. The most diverse families were Fabaceae [Relative Diversity $(R D)=11.3$, Poaceae $(R D=9.3)$ and Euphobiaceae $(R D=8)$. In terms of density, the most abundant species in the study area were Flueggea leucopvrus (Euphobiaceae) (23.3\%) and Phyllanthus polyphyllus (Euphobiaceae) $(8.6 \%)$.

Comparisons of the diversity among vegetation types showed that the degraded dry zone forest was high in diversity (Simpson's diversity index; $D=17.6$, Shannon-Wiener diversity index $\left.H^{\prime}=3.6\right)$ than rock outcrop forests $(D=10.7, \mathrm{H}=3.1)$ and scrubland $(\mathrm{D}=9.9, \mathrm{H}=3.04)$. Considering the species composition and density of flora, a Detrended Correspondence Analysis (DCA) showed the DDF as a distinct cluster, while the ROF exhibited an overlap with the DTS. A TWINSPAN cluster analysis showed that the DTS and DDF separate into two distinct clusters, which correspond to the dry and arid climatic zones. However, the ROF remained as a single major cluster.

12 Proceedings of the Seventh Annual Forestry and Environment Symposium 2001 